\title{
Evaluation of the steady state performance of a squirrel cage induction motor using per-phase equivalent circuit
}

\author{
Okafor Augustine, Olubiwe Matthew * and Akukuegbu Isdore \\ Electrical and Electronic Engineering Department, Federal University of Technology, Owerri, Nigeria.
}

World Journal of Advanced Engineering Technology and Sciences, 2022, 05(01), 001-014

Publication history: Received on 28 November 2021; revised on 01 January 2022; accepted on 03 January 2022

Article DOI: https://doi.org/10.30574/wjaets.2022.5.1.0084

\begin{abstract}
The performance evaluation of cage induction motor continues to receive tremendous attention because of its vital effect on the overall system stability. The model has predicted the behavior of cage induction motor under different operating conditions and in selecting the appropriate motor for a specific load application. There is often a challenge when a squirrel cage induction motor is connected to a time-varying load, particularly when the motor is selected without considering the effects of pulsating torques. The usual method used for steady state analysis of induction motors is the equivalent circuit method. Using the per phase equivalent circuit of the induction motor, stator current and referred rotor current were computed using simple circuit analysis. Once the currents are available, then power can be computed because the voltage is already known.
\end{abstract}

Keywords: Cage rotor induction Motor; Steady State Performance; Improved load selection; Motor sizing; Stability

\section{Introduction}

Three-phase squirrel-cage induction motors are used for different industrial applications (Examples are pump drives, reciprocating compressors, and variable speed drives). Most electrical motors are three-phase induction motors because of their low production cost, high reliability, and robust structure. Technical analyses should be done before selecting the most appropriate type of motor to provide optimum desired performance. More so, an incorrect selection of induction motor always leads to various operational challenges which include sudden motor failure. This premature motor failure causes a severe decrease in plant production. The correlation between the motor break-down torque (maximum torque) and the locked rotor torque (start-up torque) during speed-up periods should be analyzed. Careful selection of induction motor is of great significance in most industrial applications.

Induction motors are classified based on their rotor designs: squirrel cage induction motors and wound rotor (slip-ring) induction motors. During its operation, the stator is stationery while the rotor rotates. The stator has a cylindrical core covered with a metal frame. The stator core is made by stacking thin electrical steel laminations with uniformly spaced slots. The rotor consists of a cylindrical laminated iron core with uniformly spaced peripheral slots to accommodate the rotor windings [1].

The rotor conductors of a squirrel cage motor are designed in form of bars passing through slots. The rotor bars are linked to a low-resistance end ring. The starting current is high and about 5 times the normal operating current with a low power factor. Figure1 below gives a good illustration of the cage rotor and its parts.

\footnotetext{
*Corresponding author: Olubiwe Matthew

Electrical and Electronic Engineering Department, Federal University of Technology, Owerri, Nigeria.
} 


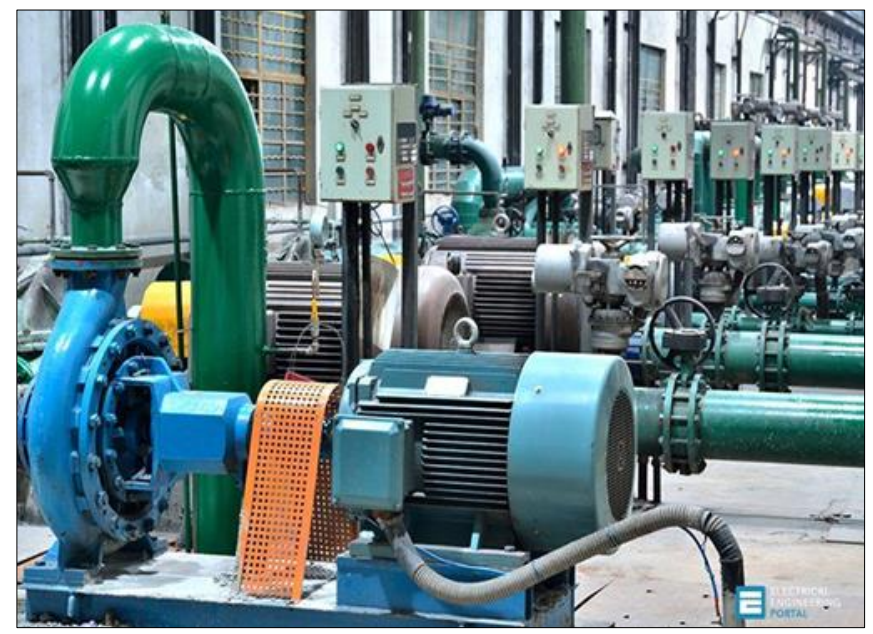

Figure 1 Industrial application of induction motors (Electrical Engineering portal)

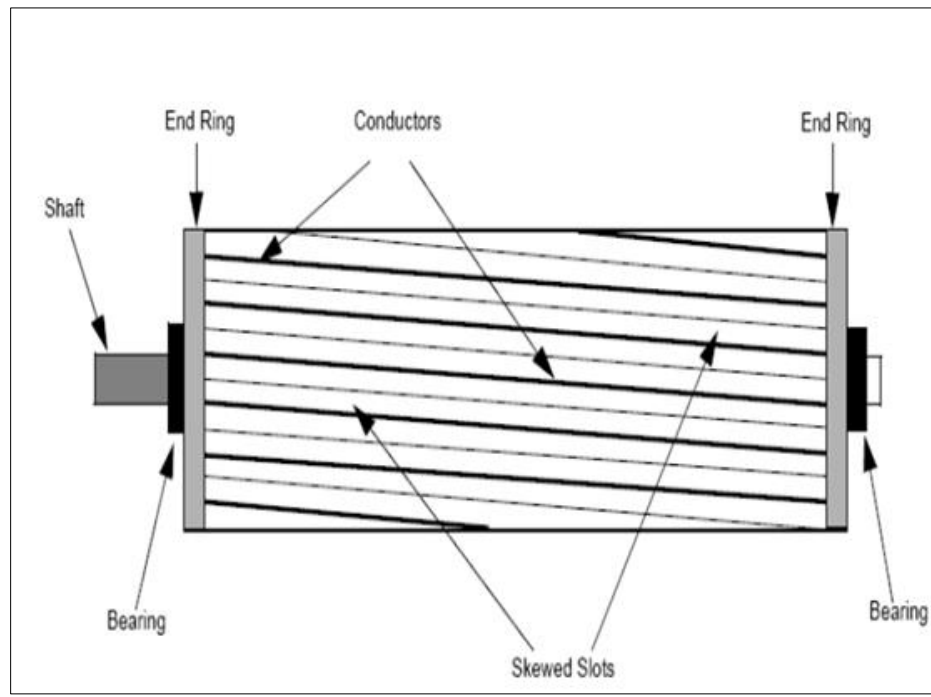

Figure 2 Squirrel Cage Rotor with skewed slots [1]

Once an ac voltage source is connected to an induction motor, a revolving flux is developed in the air gap. The interaction between the revolving flux and rotor flux causes an induced voltage in the rotor bar. The induced voltage generates rotor current that produces a flux. The rotor flux is in the reverse direction to the stator winding flux. The difference between the rotor speed and the revolving field speed is known as the slip speed.

The induction motor speed-control is challenging at light loads, the initial starting current is low, and it operates at a poor lagging power-factor. The 3-phase induction motor with a balanced input voltage can be evaluated using a singlephase equivalent circuit. During the steady-state analysis, the per-phase equivalent circuit is used for the performance analyses. Therefore, in variable-speed drives, the dynamic performance must be taken into consideration [2].

\section{Literature review}

In 1824, French physicist D.F. Arago discovered the phenomenon of rotating magnetism. He showed that a fixed copper disk on the vertical axis begins to rotate, if a permanent magnet rotates above it. Michael Faraday in 1831 explained it further and he discovered electromagnetic induction.

In 1879, Bailey W. developed a motor by replacing the rotation by alternative switching of four pole pieces connected to direct-current power supply. 
From 1890, the three-phase system became popular for a wide application of ac motors. An important phase in an induction motor is the starting, where the motor properties perform important function [3]. A good understanding of induction motor performance is a key to its optimal operation. Thesedays, simulation software is used to simulate electrical circuits where MATLAB is a typical example.

Shang (2011) proposed a comparative study of different controlled techniques of induction motor drives. The paper also examined various control methodologies, using voltage and current control.

Most research papers used various techniques like finite element method, coupling impedance method, and equivalent circuit approach to study the behavior of the induction motor driving a steady load.

In some cases, the equivalent circuit approach was used to study the performance of squirrel caged drive connected to steady load, but this technique is not valid for dynamic loads. This technique was modified to obtain the dynamic behaviors of the induction motor. In this method, an electro-mechanical system was incorporated with a two-axis ( $d$-q) equivalent circuit. It was complex approach when compared with the steady state analysis.

Ad-q model used differential equations in the d-q reference frame. The stator leakage inductance was substituted with the summation of iron-dependent saturated leakage inductance and air-dependent end-winding leakage inductance. The stator-resistance, rotor-resistance and reactance were measured using locked-rotor test.

A theoretical analysis of induction motor was done using rotating field theory for a wound rotor and squirrel cage rotor. The study showed the behavior of these motors under normal and abnormal conditions. Heller, (2014) analyzed a single broken bar with an imbalanced stator voltage using Simulink software to model the motor and the results were plotted [4].

To predict the behavior of variable-speed drives, the dynamic behavior of induction motor must be taken into consideration. Therefore, accurate mathematical evaluations are required for both transient and steady state conditions. From the results, it was observed that the two approaches produced closely related results. The $d-q$ modeling is a well-known approach for the practical implementation of vector-controlled drives [5]

A general method to derive equivalent circuit was used to determine the hunting characteristics (For example the damping and synchronizing torques) of a standard electrical machine (NNaji, 2011). A periodically pulsating loadtorque caused the speed of the motor to fluctuate. It also caused the motor current to fluctuate. The effect of these fluctuations would affect the motor or other loads connected to the busbar. It could also cause motor failure (or downtime) if not monitored and controlled to safe limits.

A motor failure would cause interruption of an industrial process, reduction in production and subsequent decrease in revenue [5]. Unexpected downtime in production plants is very expensive and therefore, prompt identification of broken rotor bars would be helpful to the plant.

\section{Material and methods}

The following methodologies were taken to achieve the objectives:

\subsection{Steady State Performance Analysis of Squirrel Cage Induction Motor}

The usual method used for steady state analysis of induction motors is the equivalent circuit method. Using the per phase equivalent circuit of the induction motor, stator current and referred rotor current are computed using simple circuit analysis. Once the currents are available, then power can be computed because the voltage is already known. The per phase equivalent circuit for induction motor is illustrated in Figure 4 below.

The flow chart of the steps used to achieve the aim is as shown below: 
World Journal of Advanced Engineering Technology and Sciences, 2022, 05(01), 001-014

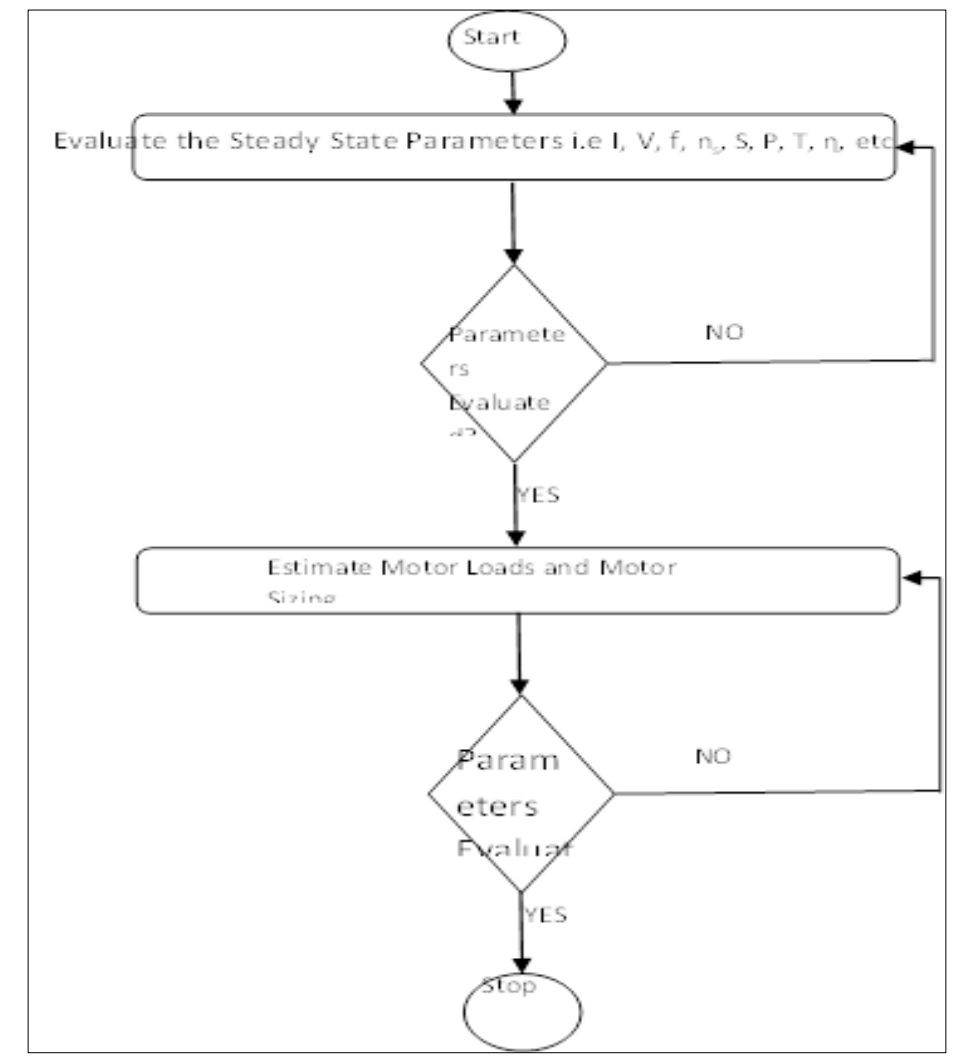

Figure 3 Flow chart of steady-state performance analysis of induction motor

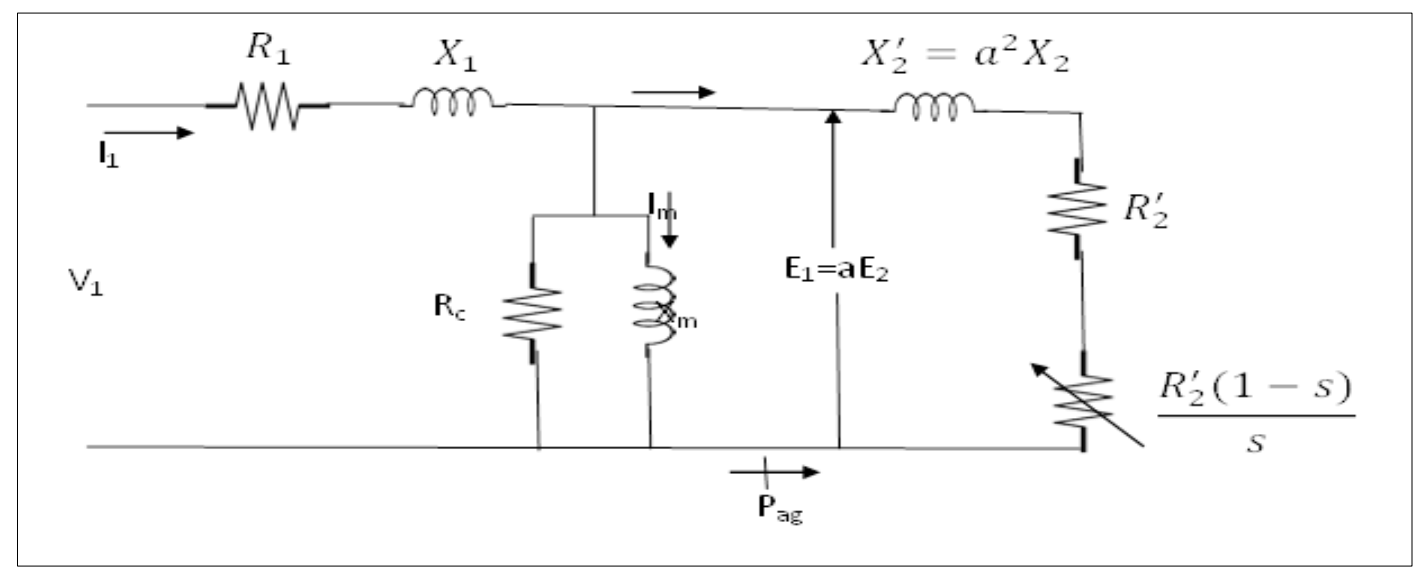

Figure 4 Per-Phase Equivalent Circuit of Induction Motor [6]

Where,

$V_{1}, R_{1}, X_{1}, I_{1}, E_{1}, R_{c}, E_{2} a n d, R_{2}$, are the per-phase terminal voltage, stator winding resistance, stator leakage reactance, stator current, induced stator voltage, stator core loss resistance, induced rotor voltage and rotor circuit resistance respectively.

While $\mathrm{I}_{2}, \mathrm{R}_{2}{ }_{2}, \mathrm{X}_{2}$, $\mathrm{I}_{\mathrm{m}}, \mathrm{X}_{\mathrm{m}}$, and $\mathrm{P}_{\mathrm{ag}}$ are the Rotor referred current, Rotor referred resistance, Rotor referred reactance, magnetizing current, Magnetizing reactance and Air-gap power respectively.

If the three-phase stator windings are connected to a three phase supply of the circuit above, a rotating magnetic field will be produced in the air gap. This rotating field induces voltages in both stator and rotor windings at an equivalent frequency $\mathrm{f}_{1}$. The magnitudes of these voltages are shown below [6]. 


$$
E_{1}=\frac{2 \pi}{\sqrt{2}} f_{1} N_{1} \phi_{p} K_{w 1}=4.44 s f_{1} N_{1} \phi_{p} K_{w 1}
$$

$$
E_{2}=\frac{2 \pi}{\sqrt{2}} f_{1} N_{2} \phi_{p} K_{w 2}=4.44 s f_{1} N_{2} \phi_{p} K_{w 2}
$$

Where,

$\phi_{p}=$ flux per pole

$K_{w 1}=$ Stator winding factor.

$K_{w 2}=$ Rotor winding factor.

$\mathrm{N}_{1}=$ number of stator winding.

$\mathrm{N}_{2}=$ number of rotor winding.

$\mathrm{f}_{1}=$ Stator frequency.

$\mathrm{f}_{2}=$ Rotor frequency.

Once the stator winding is connected to a $3 \phi$ supply and the rotor circuit is closed, the induced voltage in the rotor winding produces rotor current. This rotor current will interact with the air gap field to produce torque, the rotor will then start rotating. The rotor rotates in the direction of the rotating field and will eventually reach a steady-state speed $n$ that is less than the synchronous speed $n_{s}$. It is worthy to note that at $n=n_{s}$ there will be no induced voltage, no current and hence no torque.

Therefore, the slip $s$ and is defined mathematically as [6]

$s=\frac{n_{s}-n}{n_{s}}$

Where,

$s=$ slip.

$n_{s}=$ synchronous speed.

$n=$ rotor speed.

The frequency $f_{2}$ of the induced voltage and current in the rotor circuit will correspond to this slip rpm, Thus, we have that:

$\mathrm{f}_{2}=\frac{\mathrm{p}}{120}\left(\mathrm{n}_{\mathrm{s}}-\mathrm{n}\right) \quad=\frac{\mathrm{p}}{120} \mathrm{sn}_{\mathrm{s}}$

$\mathbf{f}_{2}=\mathbf{s f}_{1}(3)$

Where,

$s=$ Slip.

$n_{s}=$ Synchronous speed

$n=$ Rotor speed.

$\mathrm{p}=$ Number of pole pairs.

$f_{1}=$ Stator circuit frequency Hz. 
$f_{2}=$ Rotor circuit frequency Hz.

The voltage induced in the rotor circuit at slip, s, is as given below [5]

$$
E_{2 s}=\frac{2 \pi}{\sqrt{2}} f_{2} N_{2} \phi_{p} K_{w 2}(4)
$$

$=4.44 s f_{1} N_{2} \phi_{p} K_{w 2}$

$=s E_{2}(5)$

Where,

$E_{2 s}=$ The voltage induced in the rotor circuit at slip, s.

$E_{2}=$ The induced voltage in the rotor circuit. Other parameters are as defined above.

The current induced in the $3 \phi$ rotor windings produce a rotating field. Its speed (rpm) $n_{2}$ with respect to the rotor is:

$n_{2}=\frac{120 f_{2}}{p}$

$n_{2}=\frac{120 s f_{1}}{p}(7)$

$n_{2}=s n_{s}(8)$

The interaction between the stator field and the induced rotor field in the air gap produces the torque.

\subsection{Induction Motor Steady State Performance Characteristics}

The equivalent circuit shown in figure 2 above, can be used to predict the performance characteristics of the induction motor. The important performance characteristics in the steady state are the rotor current, starting torque, maximum (or pull-out) torque, power factor and the efficiency.

From the circuit in figure 2 above, the rotor current $\mathrm{I}_{2}$ is given as,

$I_{2}=\frac{s E_{2}}{R_{2}+j s X_{2}}(9)$

The power $P_{2}$ represents the rotor copper loss per phase.

$P_{2}=I_{2}^{2} R_{2}(10)$

Because induction motor is operated at low slips, the air-gap power $P_{a g}$ is as shown below:

$P_{a g}=I_{2}^{2}\left[R_{2}+\frac{R_{2}}{s}(1-s)\right](11)$

$$
=I_{2}^{2} \frac{R_{2}}{S}
$$

The speed dependent resistance $=\frac{R_{2}^{\prime}(1-s)}{s}$ (12)

Therefore, Mechanical power $P_{\text {mech }}$ :

$P_{\text {mech }}=I_{2}^{2} \frac{R_{2}}{s}(1-s)=(1-s) P_{a g}$ 
$=\left\{\frac{1-s}{s}\right\} P_{2}$

Recall from (10): $P_{2}=I_{2}^{2} \mathrm{R}_{2}=\mathrm{s} P_{a g}(14)$

Then, the mechanical power per phase $P_{\text {mech }}$ is given by:

$P_{m e c h}=T_{m e c h} \omega_{m e c h}=I_{2}^{2} \frac{R_{2}}{s}(1-s)(15)$

Where,

$P_{\text {mech }}=$ mechanical power.

$\omega_{\text {mech }}=\frac{2 \pi n}{60}$ is the mechanical speed.

$T_{\text {mech }}=$ mechanical torque.

The mechanical speed:

$\omega_{\text {mech }}=(1-s) \omega_{s}$

$=\frac{n_{s}}{60} 2 \pi(1-s)(16)$

$T_{m e c h}=\frac{1}{\omega_{s}} P_{a g}(17)$

Where,

$\omega_{s}=$ synchronous speed $=\frac{2 \pi n_{s}}{60}$

Therefore,

$P_{a g}: P_{2}: P_{m e c h}=1: s:(1-s)(18)$

Equation (18) indicates that $\mathrm{P}_{\mathrm{ag}}$ is a fraction $s$ is lost in the rotor resistance and the fraction $(1-\mathrm{s})$ is converted into mechanical power. Therefore, for efficient operation, the slip s should be reduced so that more of the $P_{a g}$ is converted into $P_{\text {mech }}$.

To evaluate the efficiency, the various losses are first identified. For a $3 \phi$ motor the power input to the stator is:

$P_{\text {in }}=3 V_{1} I_{1} \cos \theta(19)$

Where,

$\operatorname{Cos} \theta=$ The power factor. Other parameters are as defined above.

The Power loss in the stator windings is given as:

$P_{1}=3 I_{1}^{2} R_{1}(20)$

Where $\mathrm{R}_{1}$ is the ac per phase stator resistance. The power loss, $\mathrm{P}_{2}$, crosses the air gap, is given as:

$P_{2}=3 I_{2}^{2} R_{2}(21)$

Where $\mathrm{R}_{2}$ is the ac per phase rotor resistance.

The efficiency of the induction motor is given as: 
Efficiency $=\frac{p_{\text {out }}}{p_{\text {in }}}$

Where,

$P_{\text {out }}=$ The output power

$P_{\text {in }}=$ The input power

If we neglect all losses in the circuit.

Then, $\mathrm{p}_{\mathrm{ag}}=\mathrm{p}_{\mathrm{in}}(23)$

But $\mathrm{p}_{2}=\mathrm{sp}_{\mathrm{ag}}$

Therefore, $p_{\text {out }}=p_{\text {mech }}=p_{\text {ag }}(1-s)(24)$

The ideal Efficiency Eff $_{(\text {ideal) }}$ is given as [5].

$\operatorname{Eff}_{(\text {ideal })}=\frac{p_{\text {out }}}{p_{\text {in }}}=1-\mathrm{s}(25)$

The induction motor power flow diagram is as shown below:

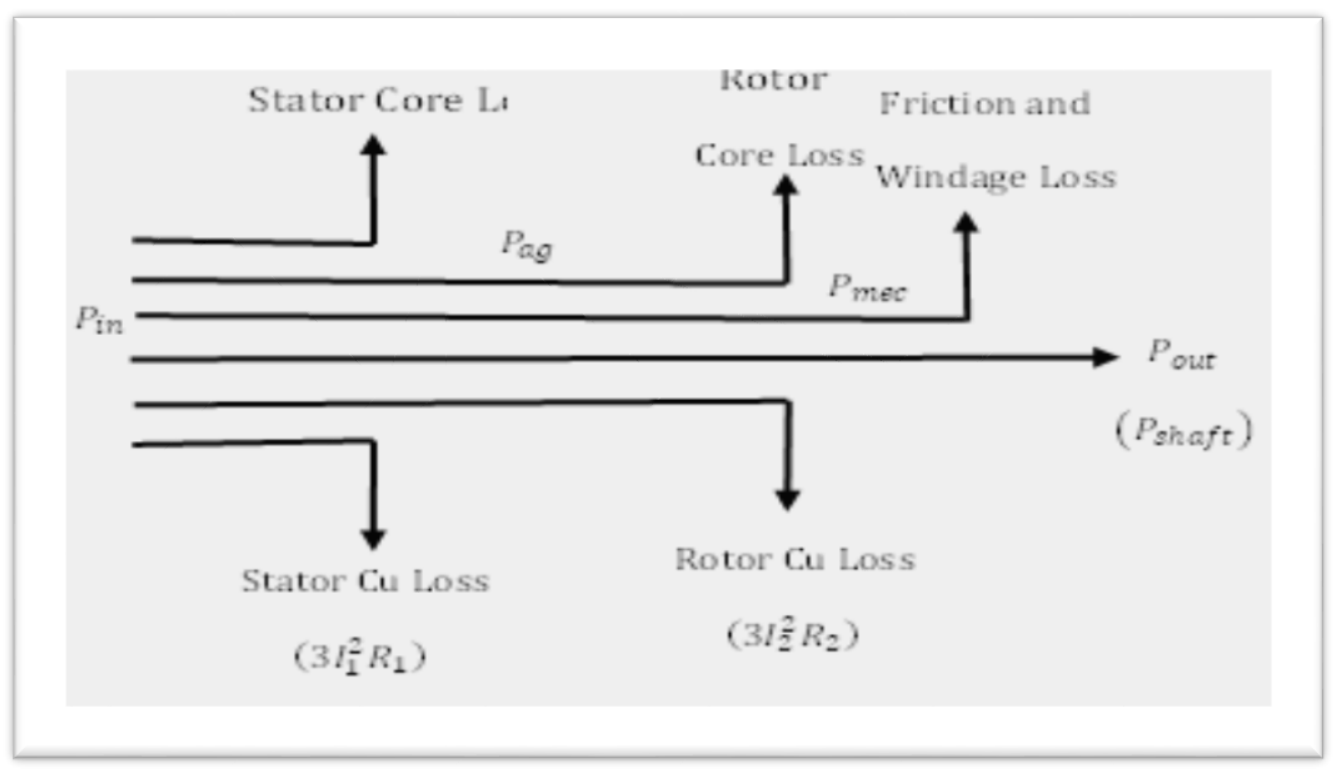

Figure 5 Power flow in an induction motor [6].

\subsection{Induction Motor Sizing Technique}

Motor sizing is the process or action of carefully choosing the right motor for a given load application. Motor sizing is important because, if a motor is wrongly selected, it may not have adequate torque to start the load. More so, excess fund is being wasted to purchase over-sized motor. Induction motors typically perform inefficiently when they operate below rated load with high running costs. Thus, if the motor speed and torque are high, the motor consumes more power. Therefore, the relationship between Power (P), Speed (N) and Torque (T) is as given below:

$P=\frac{2 * \pi * T * N}{60}(26)$

Where,

$\mathrm{P}=$ Power; $\mathrm{N}=$ Speed and $\mathrm{T}=$ Torque 
In induction motors, operating current is proportional to Torque. Once the motor surpasses the rated torque, it overheats and damages the motor windings. Therefore, Rated torque is given below:

Rated Torque $=\frac{60 * P_{\text {rated }}}{2 \pi * N_{\text {rated }}}(27)$

At constant load, motor sizing involves selecting a motor with rated torque slightly above the Load torque. The load torque should be between $75 \%-100 \%$ of the rated motor toque with $95 \%$ being an ideal choice.

Torque causes acceleration, but if the load torque is higher than motor torque, then the load will decelerate.

Hence, Accelerating Torque $=\mathrm{T}_{\text {motor }}-\mathrm{T}_{\text {load }}(28)$

Where,

$\mathrm{T}_{\text {motor }}=$ Motor Torque.

$\mathrm{T}_{\text {load }}=$ Load Torque

Therefore, for the motor to accelerate with the required load and get it up to the correct speed, then the motor torque must be higher than the load torque. The torque-speed curves below show the behavior of induction motor under various Torque conditions:

Therefore, for the motor to accelerate with the required load and get it up to the correct speed, then the motor torque must be higher than the load torque. The torque-speed curves below show the behavior of induction motor under various Torque conditions:

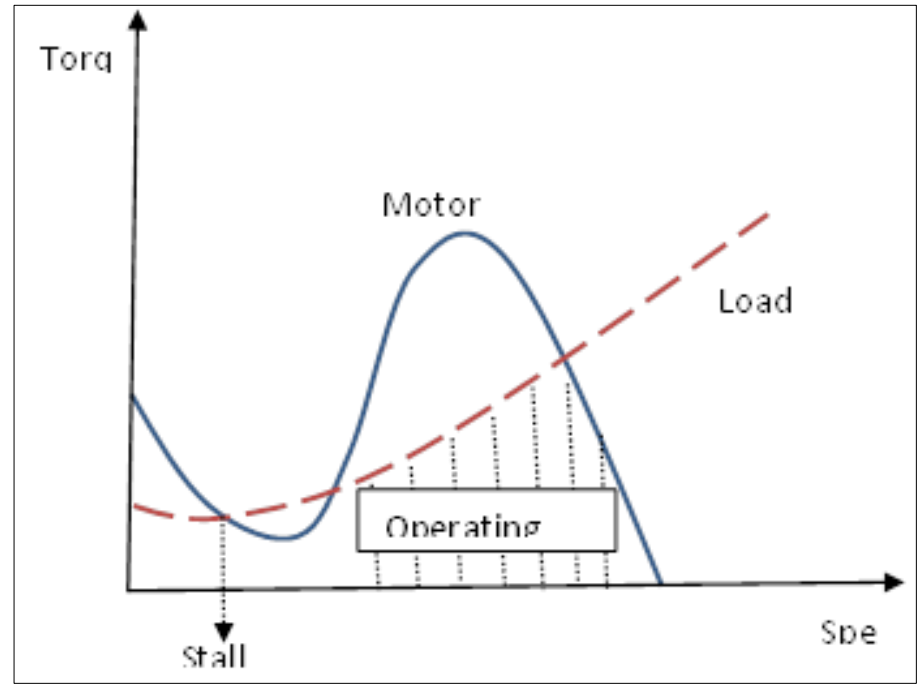

Figure 6 Behavior of induction motor when motor and load torque are the same

From the graph above, this motor will start the load but will get stucked at the stall point. This is because the load pulsating torque at that point is equal to the motor torque. 


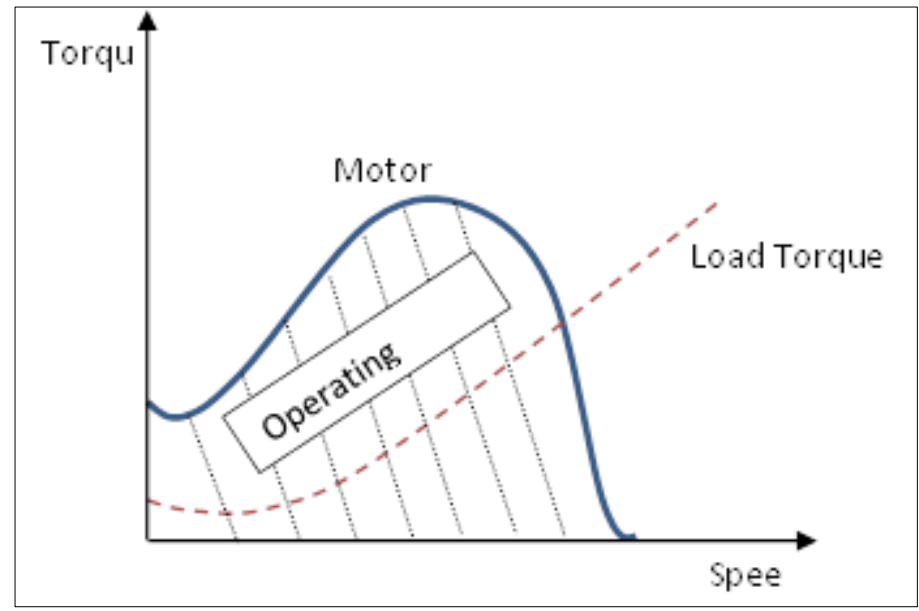

Figure 7 Behavior of induction motor when motor torque is greater than load torque

From the graph above, the motor will start and get up to the normal operating speed without getting stuck at any point. This is because the motor torque under all operating conditions is greater than the load torque.

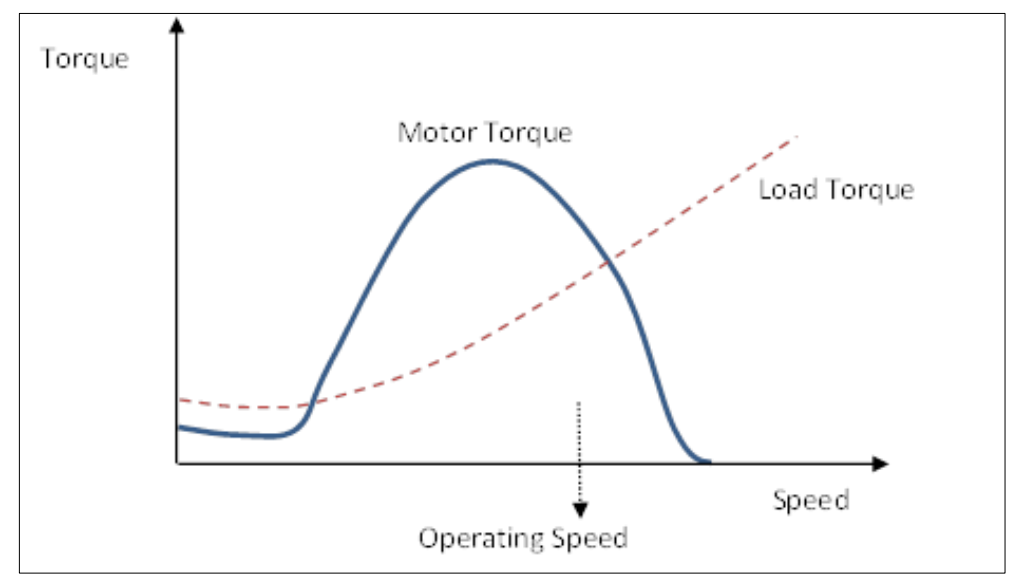

Figure 8 Behavior of induction motor when load torque is greater than motor torque

From the graph above, it is evident that under this condition, the motor will never start. If the load torque is greater than the motor torque, the cage rotor will find it difficult to rotate under such condition.

Once we experience a variable load-torque we should ensure that:

- $\quad$ Peak load torque (or power) < Rated Motor torque (or power) x $(1+$ Servicefactor $/ 100 \%)$

- The root mean square load torque (power) requirement must be less than $100 \%$ of the rated motor torque (power) and ideally greater than $75 \%$ of rated motor torque (power).

- $\quad$ Check that the Motor can start the load and get it up to speed.

For a load which requires power $\mathrm{P}_{1}$ for time $\mathrm{t}_{1}$ followed by $\mathrm{P}_{2}$ for time $\mathrm{t}_{2}$ followed by $\mathrm{P}_{3}$ for time $\mathrm{t}_{3}$ and so on up to $\mathrm{P}_{\mathrm{n}}$ for time $t_{n}$ in a cycle which repeats, the Root Mean Square Power is calculated as follows:

RMSPower $=\sqrt{\frac{P_{1}^{2} t_{1}+P_{2}^{2} t_{2}+P_{3}^{2} t_{3}+\cdots+P_{n}^{2} t_{n}}{t_{1}+t_{2}+t_{3}+\cdots+t_{n}}}(29)$

For example, the load-torque profile below was measured for a constant speed load. Choose an appropriately sized motor to drive this load assuming a service factor of $40 \%$. 


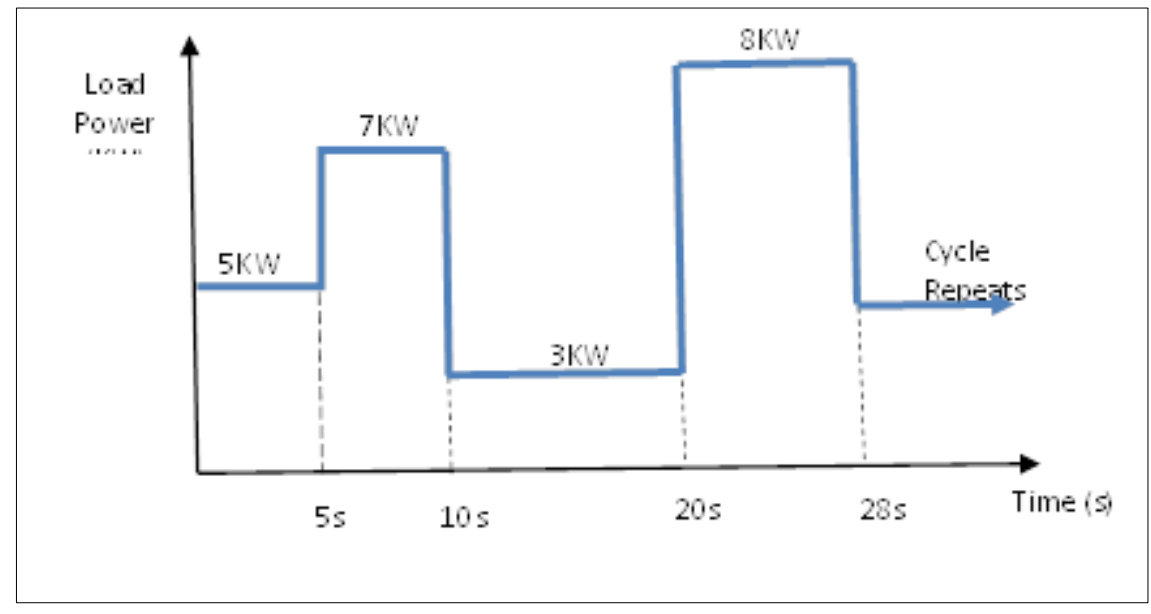

Figure 9 Load Torque Profile

\subsubsection{Sizing the motor}

STEP 1: Peak Load Power requirement $=8 \mathrm{~kW}$. Peak load power must be less than Rated Motor Power $\mathrm{x} 1+$ Service Factor.

$=>8 \mathrm{~kW}<\mathrm{P}_{\text {motor }} \mathrm{X} 1.4$

$=>P_{\text {motor }}>8 / 1.4=5.7$ approximately $6 \mathrm{~kW}$

STEP 2: Applying the 75\% -100\% of Rated Motor Power, the RMS of the load power is given as:

RMS load Power $=\sqrt{\frac{P_{1}^{2} t_{1}+P_{2}^{2} t_{2}+P_{3}^{2} t_{3}+\cdots+P_{n}^{2} t_{n}}{t_{1}+t_{2}+t_{3}+\cdots+t_{n}}}=\sqrt{\frac{5^{2} \times 5+7^{2} \times 5+3^{2} x 10+8^{2} \times 8}{5+5+10+8}}=5.89 \mathrm{KW}$

STEP 3: If we choose $P_{\text {motor }}=6.2 \mathrm{~kW}(8.3 \mathrm{Hp})$ then RMS load power $=5.89 / 6.2 * 100 \%=95 \%$ of $\mathrm{P}_{\text {motor }}$ which is acceptable. Note that, if RMS load power is less than $75 \%$ of $6.2 \mathrm{~kW}$ we should select a $6.2 \mathrm{~kW}$ ( $8.3 \mathrm{Hp}$ ) motor. However, if RMS load power is greater than $100 \%$ of rated motor power, we would select a bigger motor to meet this requirement.

\section{Results}

\subsection{Steady State Performance of a Squirrel Cage Induction Motor}

Table 1 below shows the Matlab simulation results of Torque-Speed characteristics of induction motor under constant load condition:

Table 1 Matlab results for Steady State Performance Analysis

\begin{tabular}{|l|l|l|l|}
\hline $\begin{array}{l}\text { VOLTAGE } \\
\text { (V) }\end{array}$ & $\begin{array}{l}\text { ROTOR RESISTANCE } \\
(\boldsymbol{\Omega})\end{array}$ & $\begin{array}{l}\text { STARTING TORQUE } \\
\text { (NM) }\end{array}$ & $\begin{array}{l}\text { MAX. TORQUE } \\
\text { (NM) }\end{array}$ \\
\hline 440 & 0.25 & 200 & 1400 \\
\hline 440 & 0.50 & 400 & 1400 \\
\hline 440 & 1.00 & 600 & 1400 \\
\hline 220 & 0.25 & 40 & 350 \\
\hline 110 & 0.25 & 15 & 90 \\
\hline
\end{tabular}


The graphs of figures 1, 2, 3, 4 and 5 below show the Matlab simulation results of Torque-Speed characteristics of induction motor under constant load condition:

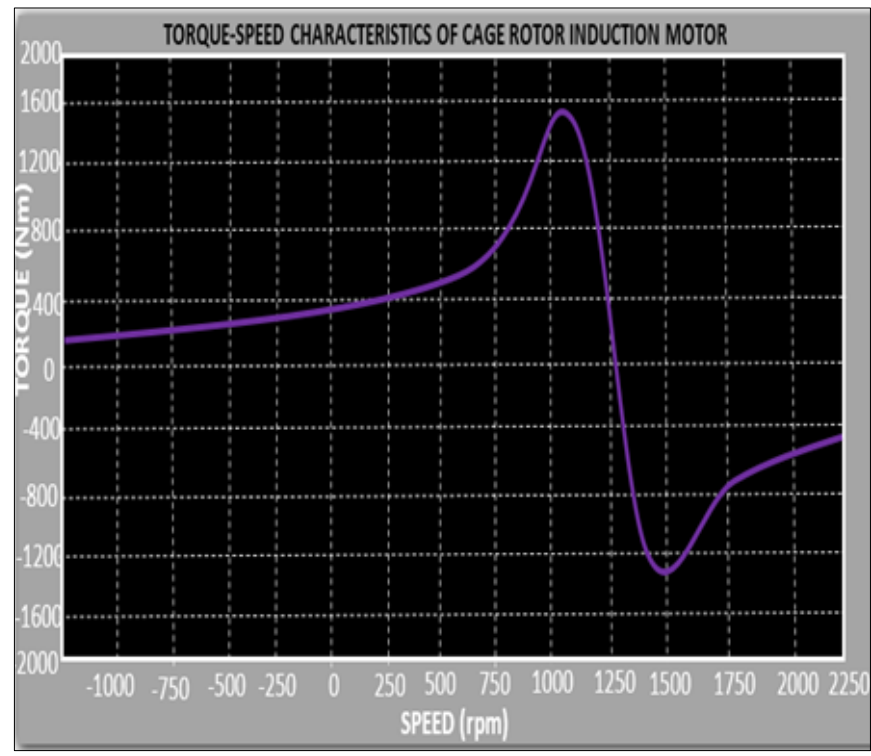

Figure 10 Torque-Speed curve at $440 \mathrm{~V}$ and $0.25 \Omega$ rotor resistance

The Torque-Speed curveabove shows that the starting torque was $200 \mathrm{Nm}$ and the maximum torque was $1400 \mathrm{Nm}$ at $0.25 \Omega$ rotor resistance. The graph shows that maximum torque is independent on the rotor resistance.

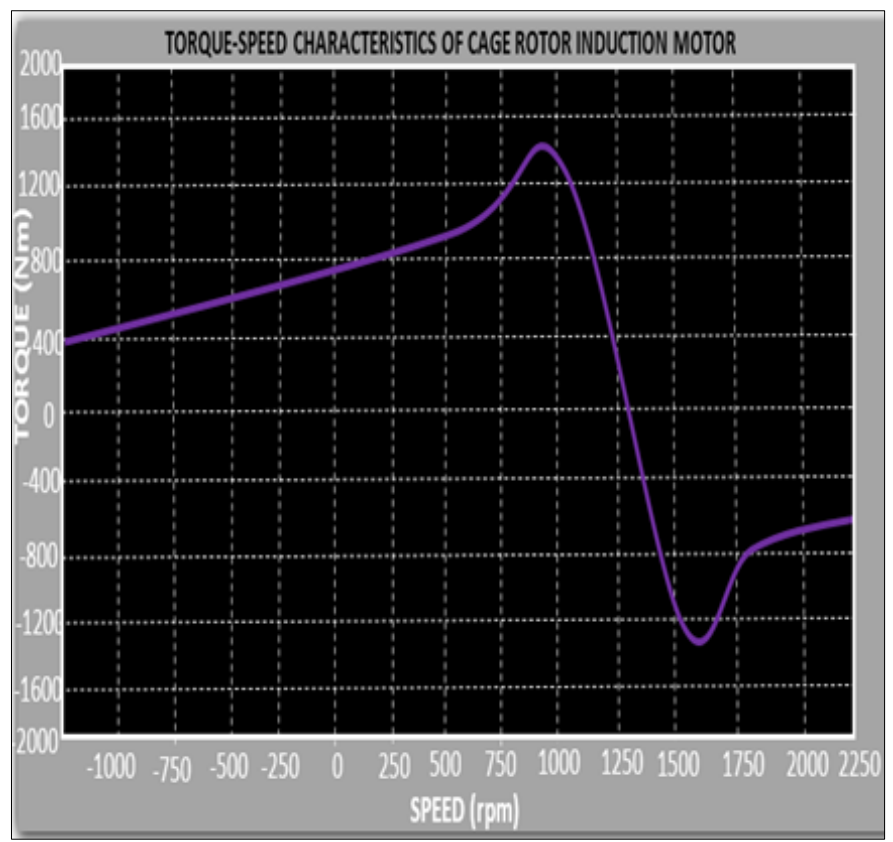

Figure 11 Torque-Speed curve at $440 \mathrm{~V}$ and $0.5 \Omega$ rotor resistance

The Torque-Speed curveabove shows that the starting torque was $400 \mathrm{Nm}$ and the maximum torque was $1400 \mathrm{Nm}$ at $0.5 \Omega$ rotor resistance. The graph shows that starting torque is dependent on the rotor resistance. 


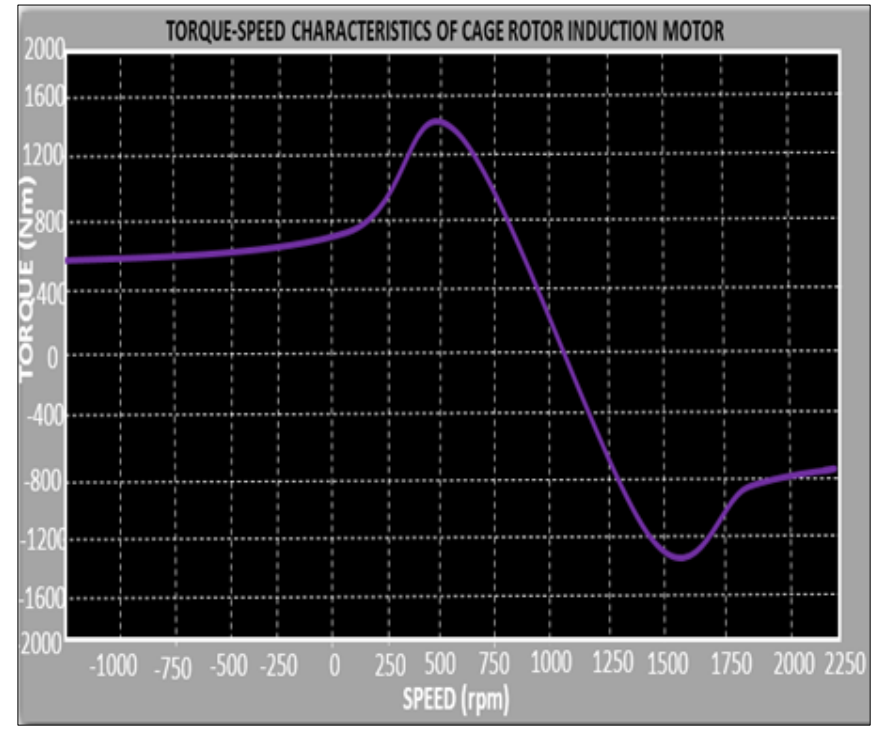

Figure 12 Torque-Speed curve at $440 \mathrm{~V}$ and $1 \Omega$ rotor resistance

The Torque-Speed curveabove shows that the starting torque was $600 \mathrm{Nm}$ and the maximum torque was $1400 \mathrm{Nm}$ at $1 \Omega$ rotor resistance. The graph shows that starting torque is only dependent on the rotor resistance since the Pull-out Torque did not change.

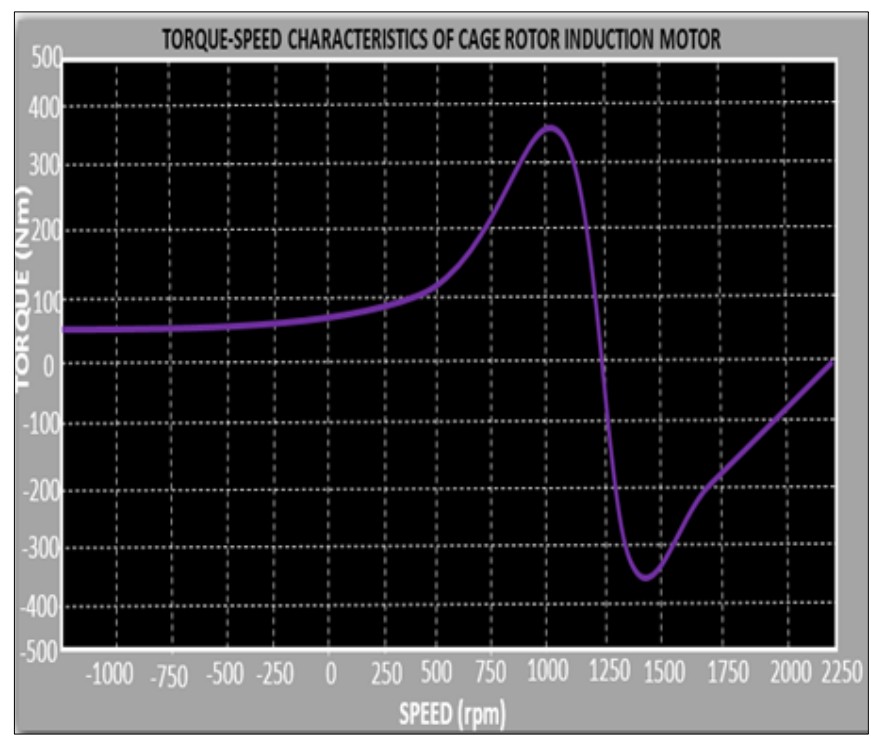

Figure 13 Torque-Speed curve at $220 \mathrm{~V}$ and $0.25 \Omega$ rotor resistance

We also observed from the graph above, that varying the voltage from $440 \mathrm{~V}$ to $220 \mathrm{~V}$, the maximum torque decreased from $1400 \mathrm{Nm}$ to $350 \mathrm{Nm}$. Also, the starting Torque decreased from $200 \mathrm{Nm}$ to $40 \mathrm{Nm}$. We can conclude that both the starting and maximum torques are dependent on the applied voltage.

\section{Conclusion}

The importance of steady-state performance analysis of induction motor cannot be over-emphasized. In this work, relevant literatures were reviewed, and the set-out objectives were achieved. The analytical approach used to analyze the motor was based on the per phase equivalent circuit. Thus, it is evident that proper sizing and selection of a motor for a specific load is key to ensuring optimum performance, reliability, and overall stability of the system. 


\section{Compliance with ethical standards}

\section{Acknowledgments}

I acknowledged the contributions made by my co-authors, the reviewers before sending for publication and the secretary who made an input during typing of the manuscript.

\section{Disclosure of conflict of interest}

All authors of this manuscript agreed and contributed meaningfully to ensure that the paper comes out successfully without any conflict of interest or grudges.

\section{References}

[1] M Naji. Dynamic Performance of cage induction motor using Harmonic Field Analysis and coupling inductances method", Research thesis university of Manchester UK. 2011.

[2] A Diaz, R Saltares, C Rodriguez, RF Nunez, J Gonzalez. Induction Motor Equivalent Circuit for Dynamic Simulation", International Conference on Electric Machines and Drives Conference. 858-863.

[3] J Lakhya, B Neelanjana. A Generalized Matlab Simulink Model of a Three Phase Induction Motor, International Journal of Innovative Research in Science, Engineering and Technology. 2015; 4(5).

[4] Z Shang. Simulation and Experiment for Induction Motor Control Strategies University of Windsor Electronic Theses and Dissertations. 2011; 5387.

[5] Anbalagan N, Chenthur S. Improving the Efficiency and Power Factor of Induction Motor using Enhanced ABC with Aid of GA. Research Journal of Applied Sciences, Engineering and Technology. 2011; 7(24): 5119-5128.

[6] PC Sen. Principles of electric machines and power electronics, 2nd ed., John Wiley \& Sons, Inc. New York.1997. 